\title{
Prácticas sonoras desbordantes. El surgimiento del ciclo Experimenta97 en Buenos Aires
}

Camila Juárez ${ }^{\star}$ y Julio Lamilla **

Resumen: El presente trabajo pretende indagar en el proceso de realización del primer ciclo de Experimenta, dirigido por Claudio Koremblit, ocurrido entre marzo y noviembre de 1997 en el Centro Cultural Ricardo Rojas de la ciudad de Buenos Aires. Este ciclo permite organizar un primer acercamiento al estudio de esas otras circulaciones de lo sonoro, en un juego de tensiones con el canon musical hegemónico local de la época. El texto intentará registrar las posibles resonancias y divergencias con otros procesos y acontecimientos históricos, en conjunto con la emergencia de incipientes teorías y prácticas sobre lo sonoro tanto a nivel local como internacional.

Palabras clave: Experimenta - Koremblit - Música Experimental - Arte Sonoro.

[Resúmenes en francés, inglés y portugués en las páginas 179-180]

${ }^{*}$ Investigadora. Licenciada en Artes y Doctora en Historia y Teoría de las Artes por la Universidad de Buenos Aires -UBA-. Ha sido becaria doctoral del CONICET. Su trabajo se enfoca en la historia cultural y política de la música de vanguardia rioplatense en la segunda mitad del siglo XX. Dicta cursos de grado y posgrado en diversas universidades. Profesora de la Universidad del Arte-UNA-, Universidad de Avellaneda-UNDAV-, Universidad de Quilmes -UNQ- y Universidad de Buenos Aires -UBA-. Integra grupos de investigación en la Universidad de Buenos Aires y ha publicado diversos artículos, entre ellos los que integran los libros The Militant Song Movement in Latin America. Chile, Uruguay, and Argentina (2014) y Tangos cultos. Kagel, JJ Castro, Mastropiero y otros cruces musicales (2012).

${ }^{(*)}$ Investigador. Licenciado en Artes por la Universidad de Playa Ancha de Ciencias de la Educación, Valparaíso, Chile. Artista sonoro. Ha expuesto en muestras colectivas como La certeza del Error, Galería Artexarte, Retrospectiva de Arte Sonoro Chileno, Parque Cultural de Valparaíso, 11 Bienal de Artes Mediales, Museo Nacional de Bellas Artes, Chile. He individualmente en MEME Gallery, Boston y Espacio G, Valparaíso. Integra el equipo de investigación del Posgrado en Lenguajes Artísticos Combinados del Depto. de Artes Visuales de la Universidad Nacional del Arte. Voluntario y co-fundador del Archivo Audiovigoteca perteneciente al Centro del Arte Experimental Vigo. Ha sido becario de Investigación de Maestría UNA y actualmente de Beca Trabucco de la Academia Nacional de Bellas Artes. 


\section{Introducción}

El ciclo "Experimenta”, dirigido por Claudio Koremblit, se desarrolló en Buenos Aires con continuidad entre los años 1997 y 2000, resurgiendo intermitentemente en los años 2005 y 2009. Se trata de un ciclo que adquiere diversas morfologías en el tiempo y que pertenece, a la vez, a una constelación más amplia de enclaves de pensamiento artístico y político tanto autogestivos como institucionales. Asimismo, con la popularización y fácil acceso a las redes digitales, dicha constelación se expande de forma rizomática y arbórea en múltiples proyectos donde ingresan también discusiones de época y aportes sonoro-intelectuales no excluyentes. Justamente "Experimenta" es un proyecto musical que reúne, como una de sus mayores virtudes, una multiplicidad de temporalidades y géneros fundados en el campo relegado de la música popular más experimental, aunque sin excluir las búsquedas académicas más radicales, y marginales, en el campo sonoro local de los noventa.

Siendo un ciclo casi inaprehensible por su constante movimiento, es a la vez huella y surco que permite trazar y eco-localizar el radio histórico de aquello que podemos denominar música experimental en Argentina. En su propia conformación como animal multiforme y desde una perspectiva de escucha local inscripta particularmente en Buenos Aires, nos preguntamos: ¿A qué se consideraba "experimental" durante los años noventa? ¿Existía, en este contexto, un campo sonoro y musical establecido ligado a dicha corriente? Estas son sólo algunas de las preguntas que disparan el presente trabajo cuyo recorte temporal será el año 1997, momento en el que se inicia la avanzada experimental.

\section{Experimenta97}

Experimenta97 nace como un Ciclo itinerante de música experimental con el financiamiento y cobijo institucional de la Secretaría de Cultura del Gobierno de la Ciudad de Buenos Aires y el Centro Cultural Ricardo Rojas de la UBA ${ }^{1}$. Distribuido en 9 capítulos, las actividades se proyectan entre los meses de marzo y noviembre de todo ese año y tienen lugar en las distintas salas de la Municipalidad de la Ciudad de Buenos Aires. Cuenta también con diversos auspicios y apoyos como por ejemplo los de las embajadas de Canadá y Australia, el de la Fundación Antorchas, además del de algunos de los proyectos del propio Koremblit tales como el programa Música de la Gran Flauta -en el aire entre 1989 y 1991-, la plataforma digital Club por la Música (1995), o la revista amiga Esculpiendo Milagros -fundada en 1992 y dirigida por Norberto Cambiasso-.

En el horizonte político neoliberal menemista es significativa la fundación -en 1997-, de diversos ciclos institucionales que persistirán en el tiempo, tales como el Ciclo de Música Contemporánea del Teatro San Martín, el Festival Internacional de Buenos Aires (FIBA) y el propio Experimenta en cuestión ${ }^{2}$. En este sentido puede pensarse en la idea de la producción de festivales y ciclos con apoyo del Estado como una política cultural que comienza a perfilarse en Buenos Aires, con el objeto de diversificar y construir un vínculo de los públicos con la cultura (Wortman, 2001, p. 258) ${ }^{3}$. Asimismo, en un contexto de mercado con una política de privatización de los medios que tienden a generar un discurso único, puede destacarse la eficacia del gobierno menemista al instalar "un nuevo imaginario en la 
Argentina" (Sarlo, en Wortman, 2002, p. 7), en relación a lo moderno en esta nueva etapa. De tal forma que:

Toda alusión a modelos políticos de transformación social y/o de acción revolucionaria no se corresponde con lo dado, con el ethos epocal o nuevo clima cultural. Han quedado desplazados al menos por el momento ciertos debates, como el papel del arte en la sociedad, la cuestión de la desigualdad cultural, etc. La crisis político cultural argentina es societal y también intelectual (Wortman, 2002, p. 7).

Sin embargo, es necesario diferenciar aquí la figura de Claudio Koremblit como un "inventor apasionado" puesto que su actividad se genera, no tanto a partir de la lógica mercantil que puede sustentar el estado en esta época, sino más bien, a través de un programa político/cultural más amplio que es incluso anterior a 1997. Ciertamente, en el texto final del catálogo de Experimenta, Koremblit afirma que:

Cada grupo de poder intenta imponer su ideología/estética y ocultar el resto de las experiencias como si no existieran (...). Tal vez pueda pensarse que la historia hablará de un resurgimiento de los valores del pasado en un tiempo de disolución de utopías (...). Y la pelea es desapareja, ellos en las redes del poder y los "nuevos" en las arenas del desierto, a ciegas, inventando nuevas realidades (Koremblit, 1997b, p. 78).

Este programa, nuevamente, puede registrarse en la cantidad de proyectos que hasta el día de hoy siguen atravesando su actividad. Es significativo mencionar entonces el desborde de su ciclo Experimenta -que tiene continuidad ininterrumpida y relativo presupuesto hasta el año 2000- en, por ejemplo, el emprendimiento ExperimentaTV ${ }^{4}$ de 2014 que incluye también otros programas -tales como Artesano de Fin de Siglo ${ }^{5}$, Pastillas de la memoria ${ }^{6}$ o el ya mencionado programa radial Música de la Gran Flauta-, o la versión online de la revista Experimenta -desde 2011-7 y el Archivo Armusa $(2016)^{8}$, para seguir actuando dentro del proyecto político/estético que reivindica estéticas marginales y desatendidas.

Puede servir también, mencionar aquí brevemente la noción de red como concepción epistemológica para pensar la forma de organización interna de Experimenta. De hecho, el tipo de trabajo colectivo establecido por una red puede ser pensado como una "forma de evitar lo instituido” (Saidón, en Poggiese, Redín y Alí, 1999, p. 156). Asimismo,

Pertenecer a una red significa trabajar con otros, formando parte de un proceso donde se intercambia información, se generan nuevos conocimientos, se potencian las experiencias, se intercambian recursos, se hacen prácticas integradas y se construyen modelos replicables para otros proyectos (Poggiese, Redín y Alí, 1999, p. 157).

El sentido en red atraviesa entonces el vasto proyecto Experimenta y sus desbordes, puesto que son convocados un conjunto de profesionales de variadas disciplinas interesados en el 
tema, a la vez que jóvenes músicos y artistas de diferentes géneros y con recursos tecnológicos múltiples, que se encuentran dispersos y desarticulados. A su vez, la misma trayectoria de Koremblit puede ser pensada en red, puesto que se transforma en el articulador de esas energías experimentales dispersas, que pueden potenciarse en el intercambio mismo de información y experiencias con otros. Así, en su propio recorrido profesional se dejan leer los pasos que llevan a la fundación de un festival, pero también que favorecen y anticipan el afianzamiento del giro sonoro-aural operado en las prácticas artísticas actuales, en un campo cultural en plena consolidación.

\section{Koremblit y la vía experimental}

En la historia de vida de Claudio Koremblit se destaca una compleja variedad de actividades centradas sobre todo, en el área audiovisual y musical. Si su gusto por la música se despunta ya a temprana edad en la casa paterna, su etapa profesional más importante comienza con la producción musical del reconocido programa de la década del ochenta Badía y Compañía, emitido por canal 13, donde ya se asoma su gusto por lo marginal, aquello que se desvía de la estabilidad de los géneros. Interesante es recalcar que dicho contexto televisivo estuvo marcado por una fuerte demanda de rapidez, donde archivos audiovisuales únicos, principalmente cintas, eran borradas por asuntos de costos, para su posterior reutilización.

En su vasta enciclopedia musical convive una amplia diversidad de músicas, desde el rock nacional y extranjero al folclore local, pasando por el tango, el jazz, el free jazz, hasta la música contemporánea de vanguardia. El mismo Koremblit recuerda su voracidad musical desde muy pequeño y sus primeras escuchas:

Mi padre era un melómano rabioso de la música argentina y del jazz. De la música argentina más progre en el folclore y el tango: Manolo Juárez, Chango Farías Gómez, Dino Saluzzi, Anacrusa, ese era el mundo de mi papá. Me llevaba de chico a escuchar estas cosas, que a mí, no me caían mal evidentemente. Eran amigos ya de él, todos los músicos se hacían amigos, porque este era un tipo que iba a todos los conciertos del Dúo Salteño por ejemplo, es decir, de tanta presencia se hacía amigo de los músicos. Era amigo de Manolo, Kelo Palacios, de Salgán, Saluzzi, amigo de ir a la casa (Entrevista realizada a Koremblit por los autores, 18/1/2018).

Ya a comienzos de los años setenta, a esta lista se suma el repertorio del rock tanto internacional como nacional, que va entrando por distintas vías de difusión, a través de revistas como Pelo, el intercambio en el parque Rivadavia, las disquerías o del entorno social más cercano:

El rock me llega como a cualquiera. En el parque Rivadavia, donde íbamos a cambiar discos. A través de mi hermano me llegan los Beatles (...). La Revista Pelo es un golpe fuerte por sus anuarios donde estaban los rankings de los 
grupos que se difundían acá: Led Zeppelin, Emerson, Lake and Palmer. A los 13 o 14 años empiezo a trabajar (...). El sueldo íntegro lo dejaba en la disquería, compraba 30 discos por mes (...). En esa boleada me entran los grupos argentinos de rock y empiezo a descubrir Invisible, Pescado Rabioso, Color Humano, son los primeros porque ya no estaba Almendra (Entrevista realizada a Koremblit por los autores, 18/1/2018).

Asimismo, retoma la línea del jazz a través de Spinetta, de la revista Expreso Imaginario y de la disquería de la editorial Atlantic en la que a finales de los setenta salen discos de free-jazz, por ejemplo Ornette Coleman. Al mismo tiempo, comienza su búsqueda por la música brasileña y académica contemporánea:

Acá, Spinetta tomaba la vía del jazz con Jade que se hace cada vez más jazzero (...). Yo me voy también para el lado del jazz. Algo de incidencia tuvo la revista Expreso Imaginario, de la cual yo era fanático, que empieza a difundir a los brasileños Egberto Gismonti y Hermeto Paschoal, a quien yo ya conocía y me enloquecía. Por ahí, por Gismonti y Hermeto, me paso al jazz y a la música brasileña, incluso escuchaba folclore. Pero abandoné el rock, no lo escuchaba más (...). Escuché a Ornette Coleman, los primeros discos que se editaron en Buenos Aires de free jazz, se habrá editado en el 78. Acá estaba la sucursal de la editorial Atlantic, (...). De ahí salían cosas muy interesantes de jazz y free jazz (...). Al mismo tiempo empecé a escuchar Stockhausen, Varese, Berio. En la disquería El Agujerito empecé a comprarme todos los vinilos, había pocas disquerías (Entrevista realizada a Koremblit por los autores, 18/1/2018).

En su relato se deja entrever su apasionado interés por la escucha sensible, el conocimiento musical, y, sobre todo, su amplitud a la hora de elegir el repertorio. Entrados ya en los años ochenta, Koremblit comienza su trabajo en la televisión como productor musical del prestigioso programa de música Badía \& Compañía, en donde estaría desde 1984 a 1988. Koremblit destaca la gran incidencia de este programa televisivo en la circulación de distintas músicas, puesto que "Badía abre el espectro musical" (Entrevista realizada a Koremblit por los autores, 18/1/2018), incluso el de la "música instrumental" que no tenía cabida en los medios con anterioridad a este programa.

Para su actividad era necesaria una profunda actualización en relación al material que circulaba a inicios del período democrático, desde Charly García, Los Jaivas, Cecilia Todd y el Cuchi Leguizamón hasta Leo Maslíah, Sumo y Batato Barea. De este modo "la música instrumental de raíz folclórica" que incluía la improvisación, denominada también "música de proyección folclórica, o fusión folclórica" pivoteadas por las figuras de "Saluzzi, el Trío de Vitale, el Chango Farías Gómez, Alfombra Mágica”, se entrelaza con el jazz, pues "Badía incluye al jazz, no solo la dixieland como la Porteña Jazz Band, sino lo instrumental más seria, el bebop, y otros, que no existían antes" (Entrevista realizada a Koremblit por los autores, 18/1/2018). Al respecto destaca que, 
Yo estaba muy al tanto de lo que circulaba en los ochenta porque era productor musical de un programa masivo que de golpe, como se había abierto la puerta democrática, nos daba licencia para llevar a la masividad cosas que nunca habían estado en la televisión. Mi función en el programa era ocuparme de lo que Badía consideraba la marginalidad, los márgenes: ¿qué eran los marginales? La buena música argentina. Lo que no era famoso ni comercial, esa era la parte que me tocaba a mí, y era lo único que me interesaba (...). Había un espacio para lo nuevo, lo desconocido (Entrevista realizada a Koremblit por los autores, 18/1/2018).

Finalmente, con la asunción de Menem en 1989, “todo se comercializó. Fue una primavera de 4 o 5 años, hasta la privatización”. En este mismo año lo despiden del programa y con la indemnización realiza dos viajes a Estados Unidos, allí explora la escena del downtown neoyorkino y descubre muchos músicos, bandas y cruces intergeneracionales. Compra discos, revistas, libros, vuelve con las valijas repletas de información que refuerza en un segundo viaje, en 1991. De esos viajes se pueden destacar, además de la experiencia vivida, el contacto con esos músicos que serían justamente muchos de los que vendrían finalmente a Experimenta97:

Viajo a Nueva York con la idea de ver a los próceres del free y del jazz, pero sobre todo del free, y qué había de nuevo (...). Ahí descubro todo este mundo, sobre todo la parte norteamericana joven que es la que veo en vivo. Empezando por Zorn, Sharp, Frisell, Kronos Quartet (...). El Kronos fue una puerta, yo los conocía de discos de David Byrne y Philip Glass (...). Empiezo a armar el rompecabezas histórico (...). El jazz, no solo el free sino lo que estaba ahí, el desarrollo de distintas corrientes del jazz, la escuela de Chicago, cómo se juntan con los rockeros de la nueva generación (...). En Nueva York estaba la no-wave (la experimentación con guitarras eléctricas, con afinaciones, eran los hijos de La Monte Young rockeros), ahí lo levanto. Justamente estos músicos, Glenn Branca, Rick Chapman, Arto Lindsay estaban tocando con la generación de los ochenta en Nueva York, los veo. Veo los cruces con lo más jóvenes del jazz libre, los viejos, las distintas corrientes. Voy al Soho a ver jazz, minimalismo. Voy a los conciertos académicos de Nueva York (Entrevista realizada a Koremblit por los autores, 18/1/2018).

Todo este conocimiento sería crucial para terminar de sintetizar las expansiones de repertorio fundamentales en Experimenta. En este sentido, el festival New Music America se suma también como una institución modélica a la cual Koremblit tiende en varios de sus proyectos. Ciertamente, es de gran importancia para la proyección del festival local dirigido por él, puesto que le permite pensar Experimenta como un ciclo inclusivo, donde se integran el rock, el jazz, la música experimental, la de vanguardia y el arte sonoro en un solo y mismo festival:

El festival New Music America fue el primer contexto donde tenías el abanico de toda la nueva música contemporánea, incluyendo las instalaciones sonoras. 
Tenías la música académica contemporánea, la música más experimental, el jazz libre, la música improvisada y el rock más ecléctico. Luego lo aplico en mi programa de radio y en Experimenta, es una marca muy fuerte para mí (Entrevista realizada a Koremblit por los autores, 18/1/2018).

De igual forma, dentro de este mismo arco temporal se inscribe también la producción de su programa radial Música de la Gran Flauta y la programación, desde los márgenes, de los primeros años de la sala Babilonia. Este último a través de varios ciclos como el "Ciclo de Nueva Música Argentina":

En ese momento no había política cultural pública, eran los comienzos del menemismo, el 89. Lo único que había era Cemento. Entonces Babilonia en los primeros 2 años creció de una manera increíble, teníamos espacio en los diarios, todo el mundo quería venir a tocar. Armé: jueves y domingo, "Nueva Música”; viernes y sábado, teatro, ciclos de jazz -uno era Babilonia Jazz- y en la trasnoche a la 1 de la mañana de los viernes y sábados, rock alternativo, ahí programé gente que conocía y emergentes (Entrevista realizada a Koremblit por los autores, 18/1/2018).

Por su parte, el programa radial Música de la Gran Flauta está en el aire de 1989 a 1991 por Radio Municipal y puede ser caracterizado como un programa fundante en la época, que aglutina al público interesado en la música más radical, muy poco frecuentada en los medios de comunicación masivos. A través de ese programa, Koremblit conoce a muchos de los músicos que luego acompañarán el movimiento de Experimenta; algunos de ellos son Federico Zypce, Alan Courtis, Carmen Baliero y Daniel Varela, entre otros. Este programa tiene gran circulación y, por su amplia llegada, "fue la mayor amplificación que tuvo esta misma música, momento en el que vuelvo de Nueva York con mi valija llena de discos" (Entrevista realizada a Koremblit por los autores, 18/1/2018). Allí mostraba los hallazgos experimentales ligados a la improvisación y la no-wave norteamericana que había descubierto en sus viajes, abriendo su desbordada enciclopedia puesto que "No había nadie en Buenos Aires que tuviera ese material" (Entrevista realizada a Koremblit por los autores, 18/1/2018). De este modo, y a través del programa radial, se favorece una vez más el conglomerado en red.

Otra experiencia que se destaca como una de sus primeras "experiencias de televisión experimental” (Entrevista realizada a Koremblit por los autores, 18/1/2018) es Artesano de fin de siglo, un ambicioso programa audiovisual de 1995, que constaba de 7 capítulos televisados por TN, realizado junto a Alberto Muñoz. Asimismo, al año siguiente realiza la producción musical del ciclo La otra música, junto a Marcelo Moguilevsky, en el teatro Margarita Xirgu, que dura un mes con fechas distribuidas por áreas temáticas: "Música abierta", "Improvisación libre", “Técnicas extendidas" y "La otra canción”. Si bien se trataba de una propuesta vinculada con la tradición experimental,

Todavía no estaba claro que íbamos a juntar experiencias de música experimental, porque no había producción en Buenos Aires. Salvo Adriana de los 
Santos o Carmen Baliero que se sumaron al proyecto inmediatamente, yo las invité, las propuse (...). Hubo una reunión general, multitudinaria, con todos los que queríamos invitar y yo empecé a delinear las temáticas y a separarlas. A juntarlos por temáticas, que todavía eran agarradas de los pelos, porque era difícil que dos se parecieran, la mayoría eran músicos populares que tenían un perfil particular (Entrevista realizada a Koremblit por los autores, 18/1/2018).

Así a través de esta trama nos acercamos, ya en los años ochenta y desde la propia trayectoria de Claudio Koremblit, a la construcción de redes de intercambio de información, saberes y experiencias con otros, desprendidas directamente de la materialidad sensible de los sonidos, de los sentidos y de la escucha.

\section{El giro sonoro}

En 1997 tiene lugar de marzo a noviembre el primer ciclo de Experimenta. El ciclo es posible gracias a las gestiones de Carmen Baliero, a la sazón coordinadora del área de música del Rojas, y del apoyo de Darío Lopérfido y Cecilia Felgueras, Secretario de Cultura y Subsecretaria de Acción Cultural del Gobierno de la Ciudad de Buenos Aires.

Si bien la práctica de Koremblit venía desarrollándose desde una perspectiva alternativa, tanto desde los seminarios impartidos en el Rojas ${ }^{9}$ como de otros recorridos ya mencionados, es Experimenta el proyecto que logra instalarse como la síntesis del trayecto recorrido. Experimenta97 se caracteriza por formar parte justamente de esa serie de intentos que habían estado aislados inicialmente y que ahora confluían para potenciar y unificar este nuevo proyecto estético-político del margen. Se trataba, esta vez, de un fuerte programa institucional, gubernamental y universitario en espacios también, convocantes y simbólicos para las músicas alternativas y académicas.

La imagen de una ventana que se abre a una información ausente o negada es usada por Claudio Koremblit para establecer uno de los objetivos del programa político-pedagógico del ciclo Experimenta97: "una ventana a la información musical del mundo, que a partir de entonces ha quedado abierta para las nuevas generaciones" (Entrevista a Koremblit, 18/1/2018). Esta entrada de aire fresco, vibración, afección, información, puede entenderse tanto como mecanismo de oxigenación de un medio afincado en la solemnidad del acto musical, las formas recurrentes y naturalizaciones, como del presentar un muestrario de otras posibilidades sonoras. En la historia tal vez mítica del arte contemporáneo, circula la imagen de Jackson Pollock rompiendo con su brazo, en un gesto de destrucción creadora, una ventana para la entrada de aire fresco (Fend, 2000, p. 175). Una especificidad del ciclo Experimenta es que a diferencia de Pollock, en su urdimbre no rompe sino que confabula, generando un pacto entre medios oficiales y una práctica artística "casi marginal o por lo menos inédita" en el medio local (Entrevista realizada a Koremblit por los autores, 18/1/ 2018).

Claramente, la idea fue recoger variedad de tradiciones y géneros que, a través de un "espíritu experimental", logran saltar las "barreras divisorias" impuestas por "dogmas y academias" (Koremblit, 1997a, p. 12). La figura que logra unir tradiciones y prácticas tan 
disímiles como el post punk, la performance y el vanguardista local Juan Carlos Paz, es la del norteamericano John Cage. De hecho, Cage sacude la estabilidad del campo musical a mediados del siglo XX, desafiando los supuestos acerca del propio estatuto de la música, las relaciones entre arte y vida, cuestionando los conceptos de sonido, ruido y silencio y las relaciones invariables entre compositor, intérprete y audiencia, además de destacar el proceso de la obra por sobre su resultado final.

En el ya clásico libro de Michael Nyman de 1974, Experimental Music, se intenta construir una historia alternativa al canon hegemónico de la denominada nueva música. Precisamente el propósito es realizar una genealogía ordenada y fundamentada de la música experimental norteamericana, en contraposición a la "música de compositores de vanguardia" europea (Nyman, 2006, p. 21). Se trata entonces de un proyecto moderno que ensaya una definición de estas tradiciones en disputa, incidiendo fuertemente en la generación de los ochenta. Así Brian Eno destaca en el Prólogo que se trataba de un acto de "entrega" hacia una música entendida como una "entidad extremadamente física, sensual, una música sin narrativa (...), libre de ser pura experiencia sonora" (Eno, 2006, p. 13), y a su vez considerada también como una "fuerte experiencia intelectual y espiritual" (Eno, 2006, p. 13). Años más tarde, en The Ashgate Research Companion to Experimental Music (2009), estudiosos dedicados al enfoque experimental comenzaron a pensar que intentar una definición unívoca de la música experimental ya no tenía mayor sentido en un momento histórico en flujo permanente. Sin embargo se rescataba el libro de Nyman puesto que, como señala Christopher Fox, había desafiado un punto central del modernismo: "que el progreso de la historia llevaba a un solo futuro y que ese futuro se hacía concreto en la obra de la vanguardia" (Fox, 2009, p. 9) ${ }^{10}$. Desde esta perspectiva, la apuesta de los nuevos autores es, más bien, prestar atención a las especificidades de cada artista, al existir una amplia variedad de prácticas inclusivas que se solapan y engullen unas a otras.

Siguiendo la idea del desborde, el ciclo Experimenta, que incluye conciertos y workshops, se expande también a través de la producción de textos de diversa naturaleza. Escritos publicados en catálogos en papel y luego en Internet firmados entre otros por los académicos Norberto Cambiasso y Omar Corrado, el músico y psiquiatra Daniel Varela, el poeta y músico Alberto Muñoz o el pintor Alfredo Prior entre otros. El programa del ciclo puede ser descifrado ya desde las primeras páginas del catálogo que se publica en marzo de ese mismo año, como otra deriva del emprendimiento de 1997. Con fragmentos bilingües, que presumen una circulación internacional, se presentan textos, traducciones originales y reflexiones de diversos autores, figuras y acontecimientos que van construyendo las claves de la idea misma del programa experimental. Las herramientas conceptuales, provenientes de la tradición norteamericana presidida por John Cage y el zen, organizan el punto de partida de una genealogía experimental selectiva, afianzando de este modo el campo de la música experimental local que se cristalizaría años después -ya en pleno uso de la información suministrada por la red de Internet-.

El repertorio elegido por el ciclo ahonda el producido en las décadas del '70 y '80 en el downtown neoyorkino, con expresiones ligadas al no-wave, post-punk, la improvisación libre, el rock experimental, free-jazz, ruido y diversos otros cruces inéditos propios de una ciudad en constante tránsito, con el propósito de entablar un diálogo entre estas expresiones y la actualidad de los noventa. Sonoridades caracterizadas por un primitivismo atonal 
disonante, que privilegia la creación de texturas ásperas, corrosivas, que por entonces circulaban en sellos del under neoyorkino como ZE Records, SST Records, RRRecords, sin edición en Argentina. Repertorio a su vez conectado a una tradición de técnicas extendidas, instrumentos preparados y no convencionales, como puede apreciarse en la selección de videos de Experimenta97 -film Fred Frith, Step Across the border, Film Harry Partch, The dreamer that remains-, y un modo de uso deconstructivo de la guitarra eléctrica, como puede verse en Elliot Sharp o Arto Lindsay, en donde el instrumento asociado de forma directa a la tradición del rock se desplaza de un abordaje convencional. Se trata aquí de experiencias sonoras situadas, alejadas de manuales y virtuosismos, músicas que abren continuamente líneas de fuga y derivas múltiples. Si bien este recorte no se contemplaba en las programaciones locales, Daniel Varela destaca que existían festivales en Amsterdam, Berlín, Zurich, Londres, Canadá, Estados Unidos o Japón (Varela, 1998) que van construyendo una corriente experimental. Se trata de un tipo de producción marginal, aunque con circuitos internacionales marcados, que pertenecen a una tradición otra: "son ellos los renegados de la música clásica contemporánea, del jazz, del rock y de cada gueto, popular o culto, donde la libertad esté condicionada por dogmas y academias" (Koremblit, 1997a, p. 12).

En el año 1997, Experimenta favorece el intercambio artístico y de información entre una veintena de compositores e instrumentistas internacionales con músicos argentinos a través de conciertos conjuntos y distintos workshops. Entre los invitados internacionales se destacan, además del japonés Kato Hideki o el minimalista James Tenney, los que han incidido en la escena neoyorkina de los años ochenta, tales como Arto Lindsay, Eliott Sharp, Zeena Parkins, Shelley Hirsch, Fred Frith, David Moss y Dave Soldier. Koremblit destaca que,

Aquellos proyectos artísticos revelaron concepciones musicales novedosas que dieron a la escena neoyorkina un carácter innovador no tan sólo en el plano del jazz, del rock y de la música improvisada, lenguajes en los cuales ya se podían percibir signos cambiantes, sino en el nivel experimental más abierto, en esa extraña marea heterogénea que los críticos norteamericanos suelen llamar "new music" y que admite a toda la música experimental que, desde mediados de siglo y John Cage mediante, sacude los aires inquietos de New York y alrededores (Koremblit s/f. "Experimenta 97").

Es decir que hay una relación entre la voz y la palabra con la tecnología, la improvisación, el ruido, la fluidez entre géneros musicales estables, lo experimental y la experiencia a partir de una percepción que se abre a la sensualidad del propio sonido.

Las ideas de indeterminación, de liberación de los sonidos a través de la sustracción del propio compositor de la obra, que es pensada más como proceso que como obra cerrada con un solo resultado, y de las libertades en las decisiones de los intérpretes, o desde la acción como esquema constructivo, se dejan leer ya desde las primeras páginas del catálogo. El texto de John Cage "Música experimental" (1957), extraído de su clásico libro Silence de 1961 inaugura el catálogo, luego de la presentación de Koremblit; se trata además de una traducción realizada especialmente para la publicación, convirtiéndose en un aporte fundamental para la recepción de las ideas del compositor en el campo cultural argentino en general. 
Lejos del deseo de comprender los sonidos, en este texto se destaca la "nueva música" como una "nueva escucha", una nueva actitud de escucha, "sólo una atención a la actividad de los sonidos” (Cage, 1997, p. 14):

Porque en esta nueva música nada tiene lugar, sólo los sonidos: los que están en la notación tanto como los que no. Los que no están en la notación aparecen en la música escrita como silencios, abriendo las puertas de la música a los sonidos que están en el ambiente. Esta apertura existe en los campos de la escultura moderna y de la arquitectura (...). Siempre hay algo para ver, algo para oír (...). Hasta que me muera habrá sonidos. Y van a seguir una vez que muera. Uno no se tiene que preocupar por el futuro de la música (Cage, 1997, p. 13).

Desde esta perspectiva podemos decir que en las tramas sociales cada vez más espectacularizadas de fines del siglo XX, donde el reino de la visión prima como régimen hegemónico de sentido ${ }^{11}$, el sonido y la escucha, como instancias y experiencias de reflexión sobre el entorno, se transforman en nutritiva fuente de indagación. Esta nueva actitud de sensibilidad sonora puede percibirse tanto en la entrega a una afección sensorial -por ejemplo en el uso de intensas densidades vibrátiles, que en el ciclo de Experimenta97 pueden apreciarse en las performances sonoras ruidistas de Elliot Sharp y Zeena Parkins, en la interpretación de la obra Broken Light de Nicolas Collins o en la inclusión de un taller de ruido e improvisación impartido por Kato Hideki, activo músico de la escena japanoise en proyectos como Ground Zero-, como por un cuestionamiento reflexivo sobre la escucha como forma de conocimiento, conciencia del entorno y zona de riesgo. Donde por ejemplo David Moss en el catálogo de Experimenta97 nos pregunta ¿Por qué los negocios de música no tienen una sección llamada "Música que usted nunca escuchó en su vida"? (Moss, 1997, p. 28). El giro sonoro, que en la práctica estética emerge con las vanguardias artísticas experimentales de mediados del siglo XX, laboratorios de música concreta y electrónica, el movimiento Fluxus y afines, y que se expande con la masificación del arte sonoro y las inabarcables posibilidades del mundo del sonido en la actualidad, se advierte ya en Experimenta como eje central, en especial en los heterogéneos abordajes tanto prácticos como conceptuales.

Es sintomático por ejemplo que en el catálogo de Experimenta97, Richard Teitelbaum en una entrevista discuta sobre el disfrute o no del ruido fuerte y cite a Max Neuhaus -uno de los precursores del arte sonoro-, en referencia a su trabajo en el espacio público. O que se seleccione de las Memorias de Juan Carlos Paz su reflexión sobre la renovación -si es posible integral-, de sus propios recursos composicionales, como ser los "elementos de relación y de contraste, marchas ambivalentes" o "hallazgos de orden imprevisible o irracional" (Paz, 1997, p. 18) y finalice diciendo "posiblemente de esa actitud de vuelco hacia la intuición, superando racionalismos extremos, dependa toda -itoda?- mi actividad futura en la composición" (Paz, 1997, p. 19). Retomando el sentido de lo experimental, en el catálogo Omar Corrado destaca la tensión entre tradición y ruptura y registra que

Los músicos incrementaron la reflexión y la acción sobre el sonido (...), aspectos disimulados o marginales en las estéticas de la representación. El pen- 
samiento radical acerca de los soportes fenomenológicos de lo sonoro puso al descubierto las convenciones operantes en el trato con las duraciones y las ocupaciones concretas de los lugares de la enunciación cristalizados en la tradición culta (...), para disponer de un campo abierto a la experiencia individual con lo inédito (Corrado, 1997, p. 21).

Es decir que, a través de estos textos, podemos intuir de alguna manera la emergencia de prácticas sonoras descalzadas del ámbito musical del concierto o de las estéticas de la representación, y que hoy se nutren de múltiples áreas del conocimiento y espacios de emplazamiento. Giro conceptual a su vez enmarcado en varios desvíos de lógicas progresivas lineales, asociadas al proyecto moderno eurocéntrico.

\section{Reflexiones Finales}

La imagen de la ventana retorna para abrir también el ciclo Experimenta como una invitación a salir de la sala, espacio conocido o reglado, desafío a aventurarse, a abandonar la academia. Experimenta, escribe Koremblit en el catálogo del '97, “abre a los jóvenes compositores un canal de información fundamental para desarrollar sus propias aventuras estéticas, promoviéndose de esta manera el surgimiento de ideas nuevas y trayectos artísticos de mayor riesgo" (Koremblit, 1997c, p. 37). En otras palabras, Experimenta97 propone abrirse a la escucha de otras sonoridades, a los ruidos -como forma tal vez de desactivar ciertos silenciamientos históricos-, al mundo cageano, al giro de la mirada lineal progresiva espectacular -la pizarra/pantalla-- hacia un borde lateral -la ventana/el entorno-. Es decir, la ventana abierta como primera condición para la percepción sonora ya no lineal desarrollista sino aural.

El giro sonoro emergente en Experimenta traduce una etapa histórica en la que el arte, de predominancia históricamente visual, cuestiona sus soportes resonantes preguntándose cómo éstos pueden ser medios transductivos de conocimiento cultural aural. En la actualidad, el uso exponencial de categorías como escultura sonora, instalación sonora, performance sonora, poesía sonora, paisaje sonoro, cuadros sonoros, caminatas sonoras dan cuenta de este giro. En los eventos musicales presentes en Experimenta97 se comienza a indagar el acontecimiento sensorial asociado al uso de altas tasas de sonoridad vibrátil, produciéndose así paulatinamente un alejamiento de los marcos de comportamiento del concierto musical. En relación a este giro sonoro la investigadora Ana María Ochoa observa:

Vivimos en una época marcada por la intensificación de lo sonoro. Por intensificación de lo sonoro me refiero a una modernidad que no se define necesariamente desde la escritura como medio primario de adquisición de conocimiento ni por modelos desarrollistas basados en una noción lineal del progreso, todo ello aunado a un "giro sónico", esto es, al "incremento significativo de lo acústico como un lugar simultáneo de análisis, de pasión y compromiso estético, y como modelo para la teorización" (Drobnick, 2004, p. 10, en Ochoa, 2011, p. 2). 
En Experimenta97 el giro sónico se produce a través de otro tipo de aproximaciones en relación a la escucha, cercanas al cuerpo, que llevarán al ciclo hacia el campo ampliado del arte sonoro. Ciertamente, Experimenta recibe una invitación del compositor mexicano Manuel Rocha Iturbide para participar del Festival Internacional de Arte Sonoro, realizado en México D.F. entre los años 1999-2002 y reconocido como uno de los primeros festivales de arte sonoro en Latinoamérica. Dicha invitación consistió en la exhibición de un recorte del proyecto Experimenta en el Festival. Asimismo, hacia el año 2000, el propio ciclo Experimenta deviene en Experimenta: Festival Internacional de Arte Sonoro y Visual. Experimenta a través de cruces sonoros inéditos y saturaciones atonales, expande la dimensión cualitativa sensual de la música, mostrando "el inconciente de la música. La piel sensible de nuestro tiempo" (Koremblit, 1997b, p. 78), prefigurando el clima de inmersión en el mar de información actual. El ciclo Experimenta97, desde una internet naciente en Argentina, se constituye tanto en archivo del pasado que invita re-experimentar el presente, como en parte fundante del giro sonoro de las artes en Argentina. De este modo, se desmarca de la mirada como régimen único de conocimiento de la experiencia estética e incluye la escucha como posibilidad de conocimiento epistemológico. Dota de un poder de sensibilidad táctil epistémica a las prácticas sonoras-aurales, a partir de una radicalización del concepto de escucha, en conjunto con una desacralización de la forma concierto musical. Por último, los distintos actores locales involucrados en el proyecto Experimenta, en actividad pero en 1997 todavía desarticulados, se presentan como entidades resistentes a la ortodoxia lineal del pensamiento musical hegemónico. Experimenta como red puede ser pensada entonces como un modo de aglutinar, construyendo un espacio vacante, aquello descentrado/marginal, que no está instituido, aquello que no está sistematizado y que no conforma, hasta ese momento, más que los fragmentos de un campo en construcción.

\section{Notas}

1. Considerado en esa época, un centro emblemático de la circulación de la cultura experimental under, relacionada fundamentalmente a las artes visuales y escénicas -con artistas como Liliana Maresca, Roberto Jacoby, Batato Barea o Gambas al Ajillo, entre otros-. 2. Tanto Experimenta como el Ciclo de Música Contemporánea del Teatro San Martín son de singular importancia para analizar la recepción de nuevas estéticas sonoro/musicales contemporáneas en el campo local, desde los años noventa.

3. Con el cambio de gobierno en 1999, la fundación de festivales sigue activa, por ejemplo con el Buenos Aires Festival Internacional de Cine Independiente (BAFICI, 1999), llegándose a sumar al día de hoy 15 festivales muy heterogéneos entre sí: http://festivales. buenosaires.gob.ar/es/home.

4. Se trata de un emprendimiento en formato televisivo y por la red de internet a través del canal alternativo Barricada TV que tiene lugar en 2014. En la página se destaca que los programas "serán realizados por un colectivo de artistas y técnicos audiovisuales sin que medie ningún interés comercial ni intercambio de dinero entre ellos, tan sólo la convicción de la necesidad de su existencia y la seguridad de que es la única manera de hacerlo ante el desinterés de los canales privados y públicos”. Allí se indica además que los mismos “mos- 
trarán un panorama de la música y el arte experimental de los últimos 20 años, atendiendo también a la totalidad de géneros y estilos contemporáneos que quedan marginados de la televisión y del Mercado" (cf, http://experimenta.biz/ExperimentaTV/?page_id=76). 5. Realizado en 1995 junto al músico y escritor Alberto Muñoz en TN (cf. http://experi menta.biz/ExperimentaTV/?page_id=76).

6. "Pastillas de la Memoria" es la primera serie de documentales musicales de Experimenta TV y el Centro Cultural Manuel Suarez, que ganó el Subsidio FOMECA Línea 6 para Micro-programas culturales. El rodaje comienza hacia junio de 2015.

7. Cf. http://experimenta.biz/revistaexperimenta/

8. La sigla corresponde al título Archivo Musical Sudamericano, dependiente del Ministerio de Cultura de la Nación cuyo lugar físico era, en 2016, el Instituto Nacional de Musicología "Carlos Vega".

(https://www.facebook.com/pg/MusicalSudamericano/about/?ref=page_internal)

9. "El anarquismo en la música norteamericana" y el "Taller de periodismo cultural alternativo" este último junto con el poeta y músico Alberto Muñoz.

10. Traducción propia del inglés.

11. "El espectáculo, como tendencia a hacer ver por diferentes mediaciones especializadas el mundo que ya no es directamente aprehensible, encuentra normalmente en la vista el sentido humano privilegiado" (Debord, 1998, s/p.).

\section{Referencias Bibliográficas}

Cage, J. (-1961-1997). “Música experimental”. En: Catálogo Experimenta 1997, vol1. Buenos Aires, Argentina. Centro Cultural Ricardo Rojas UBA/Gobierno de la Ciudad de Buenos Aires.

Corrado, O. (1997). "Fragmentos desordenados sobre la tradición experimental”. En: Catálogo Experimenta 1997, voll. Buenos Aires, Argentina. Centro Cultural Ricardo Rojas UBA/Gobierno de la Ciudad de Buenos Aires.

Debord, G. (1998). La sociedad del espectáculo. Mal de ojo. Recuperado de: https://sindo minionet/ash/espect0.htm

Donozo, L. (2009). Guía de revistas de música de la Argentina (1829-2007). Buenos Aires, Argentina. Ed. Gourmet Musical.

Eno, B. (-1974- 2006). “Prólogo”. En: Música experimental. De John Cage en adelante. Girona, España. Ed. Documenta Universitaria.

Fend, P. (2000). "Nueva Arquitectura de Matta-Clark". En: ¿Construir o deconstruir? Textos sobre Gordon Matta-Clark. Salamanca, España. Ed. Universidad de Salamanca.

Fox, C. (2009). "Why Experimental Music? Why me?” En: The Ashgate Research Companion to Experimental Music James Saunders. Londres, Inglaterra. Ed. Ashgate.

Koremblit, C. (1997a). "Experimental”. En: Catálogo Experimenta 1997, voll. Buenos Aires, Argentina. Centro Cultural Ricardo Rojas UBA/Gobierno de la Ciudad de Buenos Aires.

Koremblit, C. (1997b). “Dónde irán los ojos de nuestro tiempo?” En: Catálogo Experimenta 1997, vol1. Buenos Aires, Argentina. Centro Cultural Ricardo Rojas UBA/Gobierno de la Ciudad de Buenos Aires. 
Koremblit, C. (1997c). "Introducción a la escena experimental del sur neoyorkino”. En: Catálogo Experimenta 1997, vol1. Buenos Aires, Argentina. Centro Cultural Ricardo Rojas UBA/Gobierno de la Ciudad de Buenos Aires.

Koremblit, C. s/f. Experimenta 97. Ciclo Experimenta. Recuperado de: http://www.datamarkets.com.ar/experimenta/ii.html

Koremblit, C. (2018). La historia de Experimenta 1ª pte: Los ciclos 97, 98, 99 y 2000. Música de la Gran Flauta. [Programa de radio]. Recuperado de: https://www.mixcloud.com/ claukore/m\%C3\%BAsica-de-la-gran-flauta-presenta-la-historia-de-experimenta-1apte-los-ciclos-97-98-99-y-2000/

Moss, D. (1997). “Riesgo y Cultura 2. Un manifiesto”. En: Catálogo Experimenta 1997, vol1. Buenos Aires, Argentina. Centro Cultural Ricardo Rojas UBA/Gobierno de la Ciudad de Buenos Aires.

Nyman, M. (-1974- 2006). Música experimental. De John Cage en adelante. Girona, España. Ed. Documenta Universitaria.

Ochoa, A. (2011). "El Sonido y El Largo Siglo XX”. Bogotá, Colombia. Recuperado de: https://www.u-cursos.cl/artes/2011/0/IFUN361-110/1/material_docente/

Paz, J. C. (1997). “Situación, VI” [de Memorias I. Alturas, tensiones, ataques, intensidades]. Catálogo Experimenta 1997, voll. Buenos Aires, Argentina. Centro Cultural Ricardo Rojas UBA/Gobierno de la Ciudad de Buenos Aires.

Poggiese, H., Redín, M. E. y Alí, P. (1999). “El papel de los redes en el desarrollo local como prácticas asociadas entre estado y sociedad”. En: Los noventa. Política, sociedad y cultura en América Latina y Argentina de fin de siglo. Buenos Aires, Argentina. Ed. Eudeba/Flacso.

Varela, D. (1998). "Experimentación musical: políticas y prácticas concretas". En: Ciclo Experimenta. Recuperado de: http://www.datamarkets.com.ar/experimenta/ii.html

Wortman, A. (2001). "El desafío de las políticas culturales en la Argentina". En: Estudios Latinoamericanos sobre cultura y transformaciones sociales en tiempos de globalización 2. Buenos Aires, Argentina. Consejo Latinoamericano de Ciencias Sociales CLACSO.

Wortman, A. (2002). "Vaivenes del campo intelectual político cultural en la Argentina". En: Estudios y otras prácticas intelectuales latinoamericanas en cultura y poder. Buenos Aires, Argentina. Consejo Latinoamericano de Ciencias Sociales CLACSO.

\section{Entrevista realizada}

Claudio Koremblit. Entrevista con Camila Juárez. Buenos Aires. 18/1/2018.

Résumé : Cette étude vise à analyser le processus de réalisation du premier cycle d'Experimenta, dirigé par Claudio Koremblit, qui s'est déroulé entre mars et novembre 1997 au Centre Culturel Ricardo Rojas de la ville de Buenos Aires. Ce cycle a permis de mettre en place une première approche pour l'étude des manifestations sonores, dans un jeu de tensions avec le canon musical hégémonique local de l'époque. Le texte tentera de relever les résonances et les divergences possibles avec d'autres processus et événements historiques, 
ainsi que l'émergence de théories et de pratiques naissantes sur le son, à la fois localement et internationalement.

Mots-clés : Experimenta - Koremblit - Musique expérimentale - Art sonore.

Abstract: This paper aims to investigate the process of conducting the first event of Experimenta, directed by Claudio Koremblit, which took place between March and November of 1997 at the Ricardo Rojas Cultural Center in the city of Buenos Aires. This events allows us to organize a first approach to the study of these other sonic circulations, in a game of tensions with the local hegemonic musical canon of the time. The text will attempt to record the possible resonances and divergences with other historical processes and events, in conjunction with the emergence of incipient theories and practices on sound, both locally and internationally.

Keywords: Experiment - Koremblit - Experimental music - Sound Art.

Resumo: Este trabalho tem como objetivo pesquisar o processo de realização do primeiro ciclo da Experimenta, dirigido por Claudio Koremblit, que teve lugar entre março e novembro de 1997 no Centro Cultural Ricardo Rojas, na cidade de Buenos Aires. Este ciclo permite organizar uma primeira abordagem para o estudo dessas outras circulações do som, em um jogo de tensões com o canon musical hegemônico local da época. O texto tentará registrar as possíveis ressonâncias e divergências com outros processos e eventos históricos, em conjunto com o surgimento de teorias e práticas incipientes sobre o som, tanto local como internacionalmente.

Palavras chave: Experimenta - Koremblit - Música experimental - Arte Sonora.

[Las traducciones de los abstracts al francés, inglés y portugués fueron supervisadas por el autor de cada artículo] 